\title{
HYDROGEN-BOND DIRECTED PREPARATION AND STRUCTURES OF DIOXOVANADIUM COMPLEXES WITH TRIDENTATE SCHIFF BASES
}

\author{
HUA-NAN HU ${ }^{1}$, SHI-YONG LIU ${ }^{1, *}$, YU-PING MA ${ }^{2}$ \\ ${ }^{I}$ College of Chemistry \& Pharmacy, Taizhou University, Taizhou Zhejiang 317000, P. R. China \\ 2 Department of Chemistry, Liaoning Normal University, Dalian 116029, P. R. China
}

(Received: July 5, 2012 - Accepted: December 26, 2012)

\begin{abstract}
Two new dimeric dioxovanadium complexes, $\left[\mathrm{VO}_{2} \mathrm{~L}^{1}\right]_{2}(\mathbf{1})$ and $\left[\mathrm{VO}_{2} \mathrm{~L}^{2}\right]_{2}(\mathbf{2})$, where $\mathrm{L}^{1}$ and $\mathrm{L}^{2}$ are the deprotonated forms of the tridentate Schiff bases 2-[(2-isopropylaminoethylimino)methyl]-4-nitrophenol $\left(\mathrm{HL}^{1}\right)$ and 4-bromo-2-[(2-isopropylaminoethylimino)methyl]phenol ( $\left.\mathrm{HL}^{2}\right)$, respectively, have been synthesized and characterized by i.r., UV-Vis spectra and single crystal X-ray diffraction. There form two $\mathrm{N}-\mathrm{H} \cdots \mathrm{O}$ hydrogen bonds between two [VO $\mathrm{L}]$ moieties in each complex. The $\mathrm{V}$ atom in each complex is coordinated by the three donor atoms of the tridentate Schiff base ligand, and three oxo $\mathrm{O}$ atoms, forming an octahedral coordination.
\end{abstract}

Keywords: Synthesis; dioxovanadium complex; Schiff base; crystal structure; hydrogen bond.

\section{INTRODUCTION}

In recent years, much attention has been focused on the Schiff bases and their complexes in the fields of coordination chemistry and biological chemistry. ${ }^{1-3}$ Vanadium compounds present innumerous pharmacological applications as antitumorals, antimicrobials and insulin-mimics. ${ }^{4-6}$ It has been demonstrated that the insulin effects of promoting glucose uptake and inhibiting lipolysis can be duplicated by vanadium. It has been known that there exists trigonal bipyramidal vanadium within the phosphate-metabolizing enzyme. ${ }^{7,8}$ To further explore the role in the synthesis and the structures of such complexes, in this paper, two new dimeric dioxovanadium complexes, $\left[\mathrm{VO}_{2} \mathrm{~L}^{1}\right]_{2}$ (1) and $\left[\mathrm{VO}_{2} \mathrm{~L}^{2}\right]_{2}(2)$, where $\mathrm{L}^{1}$ and $\mathrm{L}^{2}$ are the deprotonated forms of the new tridentate Schiff bases 2-[(2-isopropylaminoethylimino)methyl]-4-nitrophenol (HL' ${ }^{1}$; Scheme 1) and 4-bromo-2-[(2-isopropylaminoethylimino)methyl]phenol (HL'; Scheme 1), respectively, were synthesized and characterized.<smiles>CC(C)NCC/N=C/c1cc(Br)ccc1O</smiles>

$\mathrm{HL}^{1}$

$\mathrm{HL}^{2}$

Scheme 1. The Schiff bases

\section{EXPERIMENTAL}

General: All chemicals used were commercially available with AR grade. Elemental analyses (CHN) were performed using a Perkin-Elmer 240 elemental analyzer. The i.r. spectra were measured with a Nicolet FT-IR 170SX spectrophotometer using $\mathrm{KBr}$ pellets in the $4000-400 \mathrm{~cm}^{-1}$ region. The EPR spectra of the complexes were measured using a Bruker EMX Micro Premium X spectrometer.

Synthesis of the Schiff Bases $H L^{1}$ and $H L^{2}$ : The two Schiff bases were synthesized according to the general method. A methanol solution $(50 \mathrm{~mL})$ of $\mathrm{N}$-isopropylethane-1,2-diamine $(1.0 \mathrm{mmol})$ was added dropwise to a stirred methanol solution $(50 \mathrm{~mL})$ of 5-nitrosalicylaldehyde or 5-bromosalicylaldehyde $(1.0 \mathrm{mmol})$. The mixture was stirred for 30 minutes and the solvent was then evaporated to give yellow oil product with quantitive yield. For $\mathrm{C}_{12} \mathrm{H}_{17} \mathrm{~N}_{3} \mathrm{O}_{3}$ (HL'): Anal. calcd., \%: C, 57.4; H, 6.8; N, 16.7. Found, \%: C, 57.2; H, 6.8; N, 16.8. For $\mathrm{C}_{12} \mathrm{H}_{17} \mathrm{BrN}_{2} \mathrm{O}\left(\mathrm{HL}^{2}\right)$ : Anal. calcd., \%: $\mathrm{C}, 50.5 ; \mathrm{H}, 6.0 ; \mathrm{N}, 9.8 \%$. Found, $\%$ : C, 50.7; H, 6.1; N, 9.8. Characteristic IR data $\left(\mathrm{KBr} ; \mathrm{v}, \mathrm{cm}^{-1}\right): \mathrm{HL}^{1} 1645$ $v(\mathrm{C}=\mathrm{N}) ; \mathrm{HL}^{2}, 1637 v(\mathrm{C}=\mathrm{N})$.

Synthesis of the Complex $\left[\mathrm{VO}_{2} \mathrm{~L}^{1}\right]_{2}(\mathbf{1})$ : A methanol solution $(5 \mathrm{~mL})$ of $\mathrm{VO}(\mathrm{acac})_{2}(0.1 \mathrm{mmol}, 26.5 \mathrm{mg})$ was added to a methanol solution $(10 \mathrm{~mL})$ of $\mathrm{HL}^{1}(0.1 \mathrm{mmol}, 25.1 \mathrm{mg})$ under stirring. The mixture was stirred at room temperature for $30 \mathrm{~min}$ to give a yellow solution. The resulting solution was allowed to stand in air for a few days. Yellow block-shaped crystals suitable for X-ray single crystal diffraction were formed at the bottom of the vessel. The isolated product was washed with cold methanol, and dried in air. Yield: $53 \%$. For $\mathrm{C}_{24} \mathrm{H}_{32} \mathrm{~N}_{6} \mathrm{O}_{10} \mathrm{~V}_{2}$ : Anal. calcd., \%: $\mathrm{C}, 43.3 ; \mathrm{H}, 4.8 ; \mathrm{N}, 12.6$. Found, \%: $\mathrm{C}$, 43.1; H, 4.9; N, 12.5. IR data $\left(v, \mathrm{~cm}^{-1}\right): 3442 \mathrm{w}, 3229 \mathrm{w}, 1644 \mathrm{~s}, 1602 \mathrm{~m}, 1568$ w, $1506 \mathrm{w}, 1464 \mathrm{~m}, 1396 \mathrm{w}, 1312 \mathrm{vs}, 1140 \mathrm{w}, 1092 \mathrm{w}, 1030 \mathrm{w}, 941 \mathrm{~s}, 844 \mathrm{~s}$, $699 \mathrm{w}, 658 \mathrm{w}, 561 \mathrm{w}, 513 \mathrm{w}, 465 \mathrm{w}$.

Synthesis of the Complex $\left[\mathrm{VO}_{2} \mathrm{~L}_{2}^{2}\right]_{2}(2)$ : The complex was prepared and crystallized according to the same method as that described for (1), with $\mathrm{HL}^{1}$ replaced with $\mathrm{HL}^{2}(0.1 \mathrm{mmol}, 28.5 \mathrm{mg})$. Yield: $61 \%$. For $\mathrm{C}_{24} \mathrm{H}_{32} \mathrm{Br}_{2} \mathrm{~N}_{4} \mathrm{O}_{6} \mathrm{~V}_{2}$ : Anal. calcd., \%: C, 39.3; H, 4.4; N, 7.6. Found, \%: C, 39.2; H, 4.5; N, 7.8. IR data $\left(v, \mathrm{~cm}^{-1}\right): 3435 \mathrm{w}, 3222 \mathrm{~m}, 1644 \mathrm{~s}, 1589 \mathrm{w}, 1540 \mathrm{w}, 1464 \mathrm{~s}, 1382 \mathrm{~m}, 1292$ s, 1182 w, 1140 w, 1085 w, 1023 w, 941 s, 851 s, 810 m, 685 w, 651 w, 562 $\mathrm{w}, 507 \mathrm{w}, 485 \mathrm{w}$.

X-Ray Single-Crystal Diffraction: Diffraction intensities for the complexes were collected at 298(2) K using a Bruker SMART 1000 CCD area-detector with MoKa radiation $(1=0.71073 \AA)$. The collected data were reduced using the SAINT program, ${ }^{9}$ and empirical absorption corrections were performed using the SADABS program..$^{10}$ The structures were solved by direct methods and refined against $F^{2}$ by full-matrix least-squares methods using the SHELXTL package. ${ }^{11}$ All of the non-hydrogen atoms were refined anisotropically. The amino $\mathrm{H}$ atoms in the complexes were located from difference Fourier maps and refined isotropically, with $\mathrm{N}-\mathrm{H}$ distances restrained to $0.90(1) \AA$, and with $U_{\text {iso }}(\mathrm{H})$ set to $0.08 \AA^{2}$. Other $\mathrm{H}$ atoms in the complexes were placed in calculated positions and constrained to ride on their parent atoms. The crystallographic data for the complexes are summarized in Table 1. Selected bond lengths and angles are listed in Table 2. Hydrogen bonds are listed in Table 3.

Table 1. Crystallographic data and experiment details for the complexes.

\begin{tabular}{|l|l|l|}
\hline & $(\mathbf{1})$ & $(\mathbf{2})$ \\
\hline Formula & $\mathrm{C}_{24} \mathrm{H}_{32} \mathrm{~N}_{6} \mathrm{O}_{10} \mathrm{~V}_{2}$ & $\mathrm{C}_{24} \mathrm{H}_{32} \mathrm{Br}_{2} \mathrm{~N}_{4} \mathrm{O}_{6} \mathrm{~V}_{2}$ \\
\hline$F w$ & 666.4 & 734.2 \\
\hline Crystal shape/colour & Block/yellow & Block/yellow \\
\hline Crystal system & Monoclinic & Monoclinic \\
\hline Space group & $P 2_{1} / c$ & $P 2_{1} / c$ \\
\hline$a, \AA$ & $12.143(3)$ & $12.563(1)$ \\
\hline$b, \AA$ & $12.295(4)$ & $12.371(2)$ \\
\hline$c, \AA$ & $9.465(2)$ & $9.264(2)$ \\
\hline$\beta$, deg & $93.322(2)$ & $107.587(2)$ \\
\hline$V, \AA^{3}$ & $1410.7(6)$ & $1372.6(4)$ \\
\hline$Z$ & 2 & 2 \\
\hline$T, \mathrm{~K}$ & $298(2)$ & $298(2)$ \\
\hline$\rho_{\text {calcd }} \mathrm{g} \mathrm{cm}^{-3}$ & 1.569 & 1.777 \\
\hline$F(000)$ & 688 & 736 \\
\hline$\mu, \mathrm{mm}^{-1}\left(\mathrm{Mo} K_{\alpha}\right)$ & 0.728 & 3.638 \\
\hline Crystal size, $\mathrm{mm}$ & $0.30 \times 0.27 \times 0.27$ & $0.23 \times 0.21 \times 0.20$ \\
\hline & & \\
\hline
\end{tabular}




\begin{tabular}{|c|c|c|}
\hline$\theta$ Range, deg & $2.36-27.00$ & $2.37-26.99$ \\
\hline Index range $(h k l)$ & $-15,12 ;-10,15 ;-11,12$ & $-16,16 ;-14,15 ;-11,11$ \\
\hline Type of scan & Multi-scan & Multi-scan \\
\hline$T_{\min ,} T_{\max }$ & $0.811,0.828$ & $0.488,0.530$ \\
\hline Reflections collected & 7996 & 8103 \\
\hline $\begin{array}{l}\text { I } \mathrm{n} d \text { e } \mathrm{p} \text { e } \mathrm{n} d \text { e } \mathrm{n} \mathrm{t} \\
\text { reflections }\left(R_{\text {int }}\right)\end{array}$ & $3064(0.0297)$ & $2968(0.0754)$ \\
\hline $\begin{array}{l}\text { Reflections with } I \geq \\
2 \sigma(I)\end{array}$ & 2179 & 1577 \\
\hline Parameters & 195 & 178 \\
\hline Restraints & 1 & 1 \\
\hline Goodness of fit on $F^{2}$ & 1.030 & 0.976 \\
\hline $\begin{array}{l}\text { Final } R \text { indeces }(I \geq \\
2 \sigma(I))^{a}\end{array}$ & $R_{1}=0.0387, w R_{2}=0.0877$ & $R_{1}=0.0500, w R_{2}=0.1021$ \\
\hline$R$ indeces (all data) ${ }^{a}$ & $R_{1}=0.0619, w R_{2}=0.0978$ & $R_{1}=0.1244, w R_{2}=0.1262$ \\
\hline $\begin{array}{l}\text { Largest diff. peak and } \\
\text { hole, } e / \AA^{3}\end{array}$ & $0.294,-0.252$ & $0.388,-0.528$ \\
\hline
\end{tabular}

${ }^{a} R_{1}=\mathrm{a}|| F_{\mathrm{o}}|-| F_{\mathrm{c}}|| \mathrm{a}\left|F_{\mathrm{o}}\right|, w R_{2}=\left[\mathrm{a} w\left(F_{\mathrm{o}}^{2}-F_{\mathrm{c}}^{2}\right)^{2} / \mathrm{a} w\left(F_{\mathrm{o}}^{2}\right)^{2}\right]^{1 / 2}, w_{1}=\left[\sigma^{2} F_{\mathrm{o}}^{2}+\right.$ $\left.\left(0.0391\left(F^{2}+2 F_{c}^{2}\right) / 3\right)^{2}+0.4982\left(F_{0}^{2}+2 F_{c}^{2}\right) / 3\right]^{-1}, w_{2}=\left[\sigma^{2} F_{0}^{2}+\left(0.0537\left(F_{0}^{2}+\right.\right.\right.$ $\left.\left.\left.2 F_{\mathrm{c}}^{2}\right) / 3\right)^{2}\right]^{-1}$.

Table 2 Selected bond lengths $(\AA)$ and bond angles $\left({ }^{\circ}\right)$ for the complexes

\begin{tabular}{|l|l|l|l|}
\hline V1-O1 & $1.9370(17)$ & V1-O4 & $1.6040(17)$ \\
V1-O5 & $1.6643(16)$ & V1-N1 & $2.157(2)$ \\
V1-N2 & $2.162(2)$ & V1-O5 & $2.3714(17)$ \\
O4-V1-O5 & $106.87(9)$ & O4-V1-O1 & $99.22(8)$ \\
O5-V1-O1 & $98.95(7)$ & O4-V1-N1 & $98.45(8)$ \\
O5-V1-N1 & $153.64(8)$ & O1-V1-N1 & $83.79(7)$ \\
O4-V1-N2 & $95.35(9)$ & O5-V1-N2 & $93.18(8)$ \\
O1-V1-N2 & $157.41(8)$ & N1-V1-N2 & $77.03(8)$ \\
O4-V1-O5 & $172.61(8)$ & O5-V1-O5 & $78.24(7)$ \\
O1-V1-O5 & $85.02(7)$ & N1-V1-O5 & $75.88(6)$ \\
N2-V1-O5 & $78.86(7)$ & & \\
(2) & & & \\
V1-O1 & $1.922(3)$ & V1-O2 & $1.602(3)$ \\
V1-O3 & $1.663(3)$ & V1-N1 & $2.158(4)$ \\
V1-N2 & $2.165(4)$ & V1-O3 & $2.409(3)$ \\
O2-V1-O3 & $106.92(17)$ & O2-V1-O1 & $100.65(17)$ \\
O3-V1-O1 & $98.69(15)$ & O2-V1-N1 & $100.42(16)$ \\
O3-V1-N1 & $151.26(16)$ & O1-V1-N1 & $84.56(14)$ \\
O2-V1-N2 & $94.05(18)$ & O3-V1-N2 & $92.65(16)$ \\
O1-V1-N2 & $157.89(15)$ & N1-V1-N2 & $76.54(16)$ \\
O2-V1-O3 & \\
O1-V1-O3 & $170.81(15)$ & O3-V1-O3 & $77.10(15)$ \\
N2-V1-O3 $3^{i i}$ & $86.70(13)$ & N1-V1-O3 & $74.59(13)$ \\
& $77.37(14)$ & & \\
& & &
\end{tabular}

*Symmetry codes: ${ }^{\mathrm{i}}-x,-y,-z$;i $1-x, 1-y, 1-z$

Table 3 Hydrogn-bond geometry $\left(\AA,{ }^{\circ}\right)$ for the complexes.

\begin{tabular}{|c|c|c|c|c|}
\hline$D-\mathrm{H}^{\cdots} A$ & $D-\mathrm{H}$ & $\mathrm{H} \cdots A$ & $D \cdots A$ & $D-\mathrm{H}^{\cdots} A$ \\
\hline$(\mathbf{1})$ & & & & \\
\hline $\mathrm{N} 2-\mathrm{H} 2 \cdots \mathrm{O} 1^{\mathrm{i}}$ & $0.90(1)$ & $2.32(2)$ & $3.053(3)$ & $139(3)$ \\
\hline $\mathrm{N} 2-\mathrm{H} 2 \cdots 5^{\mathrm{i}}$ & $0.90(1)$ & $2.37(3)$ & $2.884(3)$ & $117(2)$ \\
\hline$(\mathbf{2})$ & & & & \\
\hline $\mathrm{N} 2-\mathrm{H} 2 \cdots \mathrm{O} 1^{\mathrm{ii}}$ & $0.90(1)$ & $2.36(3)$ & $3.084(5)$ & $138(4)$ \\
\hline $\mathrm{N} 2-\mathrm{H} 2 \cdots 3^{\text {ii }}$ & $0.90(1)$ & $2.32(4)$ & $2.865(5)$ & $119(4)$ \\
\hline
\end{tabular}

Symmetry codes: ${ }^{\text {i }}-x,-y,-z$; ii $1-x, 1-y, 1-z$

\section{RESULTS AND DISCUSSION}

The Schiff bases $\mathrm{HL}^{1}$ and $\mathrm{HL}^{2}$ were prepared via the reaction of equimolar quantities of $\mathrm{N}$-isopropylethane-1,2-diamine with 5-nitrosalicylaldehyde and 5-bromosalicylaldehyde, respectively, in methanol (Scheme 2). The two dioxovanadium complexes were readily synthesized according to the standard procedure (Scheme 3), crystallized as yellow crystals, which are stable in air at room temperature. The crystals of the complexes are soluble in DMSO, DMF, $\mathrm{MeCN}, \mathrm{MeOH}$ and $\mathrm{EtOH}$, insoluble in water. The vanadium in both complexes are +5 oxidation state and therefore EPR silent.<smiles>[X]c1ccc(O)c(C=O)c1</smiles>

Scheme 2. The synthesis of the Schiff bases. $\mathrm{X}=\mathrm{NO}_{2}$ for $\mathrm{HL}^{1}$ and $\mathrm{X}=$ $\mathrm{Br}$ for $\mathrm{HL}^{2}$

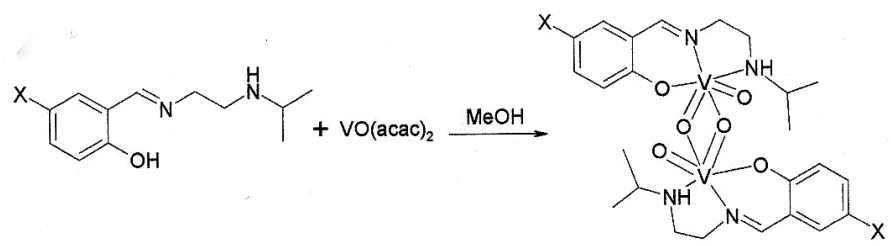

Scheme 3. The synthesis of the complexes. $\mathrm{X}=\mathrm{NO}_{2}$ for (1) and $\mathrm{X}=\mathrm{Br}$ for (2)

Structure Description of the Complexes: The molecular structures of the complexes (1) and (2) are shown in Figures 1 and 2, respectively. Each complex is a centrosymmetric dimeric dioxovanadium(V) compound, with the inversion center located at the midpoint of the two $\mathrm{V}$ atoms. The $\mathrm{V} \cdots \mathrm{V}$ distances are 3.163(1) $\AA$ for (1) and 3.218(1) $\AA$ for (2). Each $V$ atom in the complexes is six-coordinated through three bonds to oxo groups and through bonds to the tridentate Schiff base ligand, forming an octahedral geometry. The $\mathrm{V}$ atoms lie 0.344(2) $\AA$ for (1) and 0.359(2) $\AA$ for (2) from the mean planes defined by the equatorial donor atoms, in the direction of the axial oxo ligands. The V1-O4 and V1-O5 distances in (1) and the V1-O2 and V1-O3 distances in (2) indicate that they are typical $\mathrm{V}=\mathrm{O}$ double bonds. The $\mathrm{O} 5$ atom in (1) and $\mathrm{O} 3$ atom in (2) are involved in the bridges between the two $\mathrm{V}$ atoms. The coordinate bond lengths in the complexes are comparable to each other, and also similar to those observed in dimeric oxovanadium complexes. ${ }^{12-15}$ The distortion of the octahedral coordination can be observed by the coordinate bond angles, ranging from $75.9(1)$ to $106.9(1)^{\circ}$ for (1) and from 74.6(1) to $106.9(2)^{\circ}$ for (2) for the perpendicular angles, and from 153.6(1) to 172.6(1) ${ }^{\circ}$ for (1) and from 151.3(2) to $170.8(2)^{\circ}$ for (2) for the diagonal angles. There form four intermolecular $\mathrm{N}-\mathrm{H} \cdots \mathrm{O}$ hydrogen bonds between the two [ $\mathrm{VO}_{2} \mathrm{~L}$ ] moieties in the complexes.

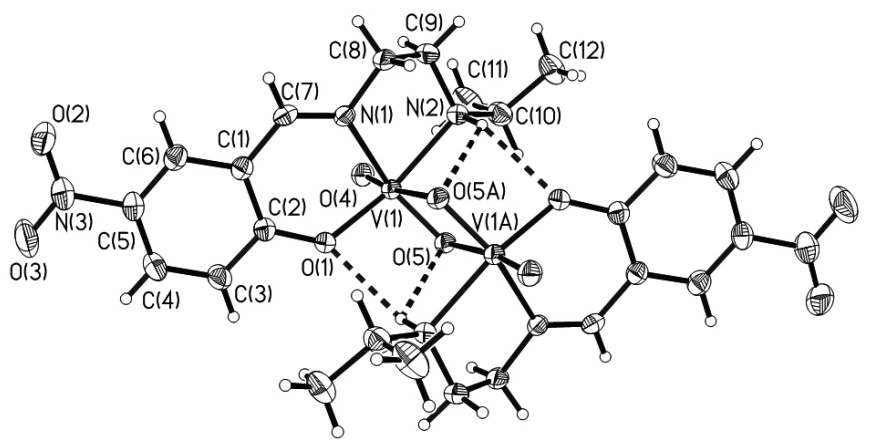

Figure 1 Molecular structure of complex (1) at 30\% probability displacement. Atoms labeled with the suffix A are at the symmetry position $-x,-y,-z$. 


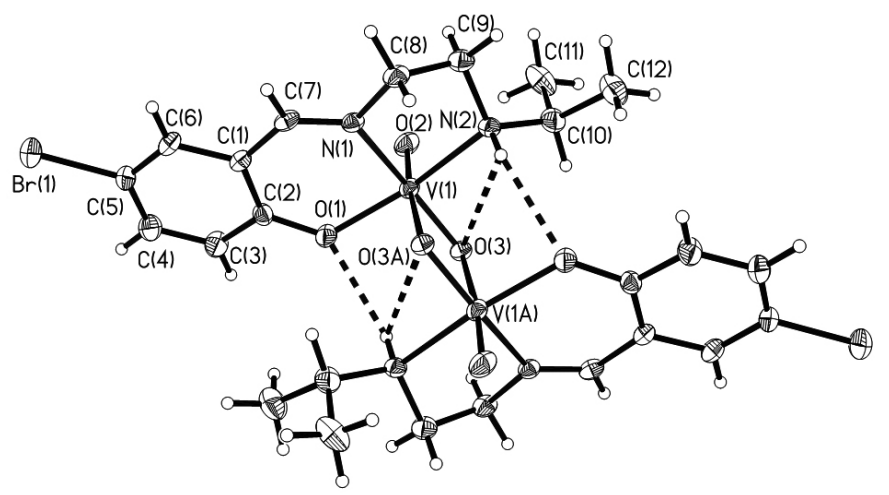

Figure 2 Molecular structure of complex (2) at 30\% probability displacement. Atoms labeled with the suffix A are at the symmetry position $1-x, 1-y, 1-z$

\section{CONCLUSION}

In the present paper, two new dioxovanadium complexes have been synthesized and characterized by X-ray diffraction. The Schiff bases 2-[(2-isopropylaminoethylimino)methyl]-4-nitrophenol and 4-bromo-2-[(2isopropylaminoethylimino)methyl]phenol coordinate to the $\mathrm{V}$ atoms through the phenolate $\mathrm{O}$, imine $\mathrm{N}$ and amine $\mathrm{N}$ atoms. The hydrogen bonds play an important role for the construction of dimeric structures during the selfassembly of the complexes.

\section{Supplementary material}

Supplementary material CCDC -858864 for (1) and 858865 for (2) contain the supplementary crystallographic data for this paper. These data can be obtained free of charge at http://www.ccdc.cam.ac.uk/const/retrieving.html or from the Cambridge Crystallographic Data Centre (CCDC), 12 Union Road, Cambridge CB2 1EZ, UK; fax: +44(0)1223-336033 or e-mail: deposit@ccdc. cam.ac.uk.

\section{ACKNOWLEDGEMENTS}

We acknowledge the Natural Science Foundation of China (21244008) and the Zhejiang Provincial Natural Science Foundation of China (LY12B02004) for funding this work.

\section{REFERENCES}

1. L. Shi, W.-J. Mao, Y. Yang, H.-L. Zhu, J. Coord. Chem. 62, 3471, (2009).

2. K. Cheng, Q.-Z. Zheng, Y. Qian, L. Shi, J. Zhao, H.-L. Zhu, Bioorg. Med. Chem. 17, 7861, (2009).

3. Z.-L. You, D.-H. Shi, C. Xu, Q. Zhang, H.-L. Zhu, Eur. J. Med. Chem. 43, 862, (2008).

4. M. Xie, L. Gao, L. Li, W. Liu, S. Yan, J. Inorg. Biochem. 99, 546, (2005).

5. C. Orvig, P. Caravan, L. Gelmini, N. Glover, F.G. Herring, H. Li, J.H. McNeill, S.J. Rettig, I.A. Setyawati, J. Am. Chem. Soc. 117, 12759, (1995)

6. A.M.B. Bastos, J.G. da Silva, P.I.S. da Maia, V.M. Deflon, A.A. Batista, A.V.M. Ferreira, L.M. Botion, E. Niquet, H. Beraldo, Polyhedron 27, 1787, (2008)

7. B. Borah, C.W. Chen, W. Egan, M. Miller, A. Wlodawer, J.S. Cohen, Biochemistry 24, 2058, (1985).

8. L.M. Mokry, C.J. Carrano, Inorg. Chem. 32, 6119, (1993).

9. Bruker, SMART (Version 5.628) and SAINT (Version 6.02); Bruker AXS Inc: Madison, Wisconsin, USA, (1998).

10. G.M. Sheldrick, SADABS Program for Empirical Absorption Correction of Area Detector, University of Göttingen, Germany, (1996).

11. G.M. Sheldrick, SHELXTL V5.1. Software Reference Manual; Bruker AXS, Inc: Madison, Wisconsin, USA, (1997).

12. Z.-L. You, D.-M. Xian, M. Zhang, H. Sun, H.-H. Li, Chin. J. Inorg. Chem. $28,1271,(2012)$

13. E. Kwiatkowski, G. Romanowski, W. Nowicki, M. Kwiatkowski, K. Suwinska, Polyhedron 26, 2559, (2007)

14. A.W. Addison, T.N. Rao, J. Reedijk, J. van Rijn, G.C. Verschoor, J. Chem.
Soc. Dalton Trans. 1349, (1984).

15. C.A. Root, J.D. Hoeschele, C.R. Cornman, J.W. Kampf, V.L. Pecoraro, Inorg. Chem. 32, 3855, (1993).

16. Z.-L. You, D.-H. Shi, J.-C. Zhang, Y.-P. Ma, C. Wang, K. Li, Inorg. Chim. Acta 384, 54, (2012).

17. Z.-L. You, H. Sun, B.-W. Ding, Y.-P. Ma, M. Zhang, D.-M. Xian, J. Coord. Chem. 64, 3510, (2011). 